\title{
Interaction of bio-coke with different coal tar pitches
}

\author{
X. Huang, D. Kocaefe*, Y. Kocaefe, D. Bhattacharyay \\ Université du Québec à Chicoutimi \\ 555, boul de l’Université, Chicoutimi Québec Canada G7H 2B1 \\ X.Huang <xianai.huang1@uqac.ca>, \\ D. Kocaefe <duygu_kocaefe@uqac.ca>, \\ Y. Kocaefe<yasar_kocaefe@uqac.ca>, \\ D. Bhattacharyay < dipankar.bhattacharyay@uqac.ca >
}

\begin{abstract}
:
The interactions of pyrolysed and calcined bio-cokes with three coal tar pitches of different properties were studied using a sessile drop test at $170^{\circ} \mathrm{C}$. A model was employed to characterize and quantify the spreading and penetration of pitch into bio-coke bed. The pyrolysed bio-cokes were produced from softwood materials by heat treatment at $426^{\circ} \mathrm{C}$. The calcined bio-cokes were produced by calcining the pyrolysed bio-coke at $1200^{\circ} \mathrm{C}$. Optical microscope, SEM/EDS, XRD, and FTIR techniques were used to analyze the coke-pitch interface and study their interaction mechanisms. The results show that the wettability of bio-coke is related to both pitch and coke properties. It is found that the presence of small amount of uniformly distributed small size quinoline insolubles (QI) in pitch seems to help pitch spread and penetrate into the bio-coke bed. Besides, calcination changes the chemical structure of bio-coke, enriches its carbon (C \%) content, increases its crystalline length (Lc), and lowers its wettability by pitch.
\end{abstract}

\section{Introduction}

Bio-coke is a carbon product derived from biomass materials, which have renewable, low cost, sulfur free, and inexhaustible supply evenly distributed throughout the globe [1]. Different biomass materials are used to generate bio-carbon materials for different applications according to specific demands [2, 3]. The utility of biocarbon materials in many major technologies has been studied $[4,5]$. Activated bio- carbon materials are mostly used as sorbents in environmental protection due to their high specific surface area, consequently, their high absorption capacity [6]. Bio-cokes made from different biomass materials are used in preparation of electrodes for energy storage [1, 7-15]. It was reported that the electrodes produced with bio-coke and bio-pitch by pyrolysis of eucalyptus wood had comparable electrical and mechanical properties to those made with conventional carbonaceous materials [7]. The electrodes made from babassu coconut based bio-carbon material had similar Young's modulus and rupture strength compared to those of the electrodes produced using conventional cokes [14].

The carbon anodes consumed during the alumina electrolysis can be considered as composites, which consist of filler petroleum coke and recycled material (recycled anodes and butts) as skeleton and the binder coal tar pitch as binder $[7,16,17]$. The demand for petroleum coke used in aluminum industry as the main raw material is substantial; however, it is becoming harder to find good quality anode grade coke. During anode production and electrolysis, greenhouse gas (GHG) emissions take place. Aluminum industry is continuously working to decrease these emissions. It might be worthwhile to consider the utilization of bio-coke as a new, sulfur-free renewable source of coke which can contribute to further reduction of GHG emissions [1]. Thus, there might be a potential for partial replacement of petroleum coke with bio-coke, produced by biomass materials and a renewable natural resources [8]. There are very a few publications regarding the utility of bio-coke as anode raw material for aluminum industry $[11,18]$. It was reported that the low density of bio-cokes produced from maple and spruce affected the anode properties adversely and it did not decrease significantly the $\mathrm{CO}_{2}$ emissions during electrolysis [11]. Huang et al. carried out structural and morphological characterization of two bio-cokes and showed that the bio-coke has a suitable structure to be used as raw material for anodes [18].

Coke/pitch interactions taking place during anode fabrication define the final anode quality. Therefore, producing a good quality carbon anodes requires a good understanding of these interactions [19]. The pitch is expected to wet the surface of coke and to penetrate through its pores while raw materials are mixed during anode fabrication. Strong interactions contribute to the quality of binding. Thus, both wetting and penetration (flow) should be taken into account when coke/pitch interactions are studied [20]. Penetration is a rheological or dissipative property of pitch [19]. Studies on wettability of coke by pitch are of considerable importance [21]. The wettability test can be performed under non-isothermal or isothermal conditions. A number of investigations were carried out on the wettability of petroleum coke by pitch at different temperatures [17, 1928]. Several methods were used for estimating the ability of a molten pitch to penetrate into a coke bed [20, 21 , $25,27]$. The temperature at which the contact angle between a pitch droplet and a bed of fine coke particles 
becomes $90^{\circ}$ is defined as the wetting temperature of the pitch obtained from non-isothermal tests. Experiments carried out under isothermal conditions showed that the contact angle continuously decreases, [23, 28] with time. The dynamic wetting of bio-coke by pitch is not fully understood. Moreover, there is no quantitative study on the spreading and penetration properties of pitch on petroleum coke. The information on interactions of biocoke and different pitches is very valuable to assess the possibility of using bio-coke as a potential anode raw material and to establish if a given pitch can be used to produce anodes using a specific bio-coke for the aluminum industry. However, not much information is available on the wettability of bio-cokes by different coal tar pitches. The reason is that bio-cokes usually have a low density and high porosity compared to petroleum coke, which might increase the pitch requirement, and consequently increase the cost of anode production, and decrease the anode quality [11]. Recently, a more careful selection of feedstock and the development of new processes have made it possible to obtain bio-cokes with suitable characteristics to be used as filler. To the authors' knowledge, the published literature about the interaction between bio-coke and pitch during mixing is still lacking. Moreover, detailed and comprehensive studies on wetting and penetration of pitch into bio-coke and chemical analysis of bio-coke/pitch interface are not available in the literature.

In this work, the interaction mechanism of three different types of coal tar pitches with bio-cokes before and after calcination are studied by means of a sessile drop test, optical microscopy (OPM) and scanning electron spectroscopy with X-ray microanalysis (SEM/EDS), Fourier transform infrared spectroscopy (FTIR) and X-ray Diffraction (XRD). The wetting and penetration behavior was characterized by initial contact angle, total wetting time, dynamic contact angle, and penetration and spreading rate constant (K-value) obtained from a dynamic wetting model for porous materials [29, 30]. The effect of the structure and chemical properties of the pitches and bio-cokes on their interaction was also studied. The relationships of pitch penetration and spreading capacity with the characteristics of pitches and bio-cokes are discussed with the aim of identifying suitable biocoke/pitch pairs.

\section{Experimental}

\subsection{Materials}

In this study, three commercially available coal tar pitches, presently used in aluminum industry, with different properties have been selected as the binder. The main physical and chemical characteristics of the pitches are given in Table 1. The values were provided by the supplier. Differences in their quinoline insoluble (QI) contents are found to be significant.. However, $\beta$-resins and toluene insoluble (TI) contents of all three pitches are similar e. The pitch viscosities are also different. This most probably affects wettability of coke by these pitches. Besides, inorganic impurities, such as $\mathrm{Na}$ and $\mathrm{Ca}$, also might influence the pitch/bio-coke interactions [22].

Table 1 Properties of pitches used in the study

\begin{tabular}{lccc}
\hline \multirow{2}{*}{ Properties } & \multicolumn{3}{c}{ Coal tar pitch } \\
\cline { 2 - 4 } & Pitch-1 & Pitch-2 & Pitch-3 \\
\hline Quinoline insolubles $(\% \mathrm{~m} / \mathrm{m})$ & 6.9 & 7.5 & 10.8 \\
Toluene insolubles $(\% \mathrm{~m} / \mathrm{m})$ & 29.1 & 29.6 & 33.0 \\
$\beta$ Resin $(\% \mathrm{~m} / \mathrm{m})$ & 22.2 & 22.1 & 22.2 \\
Density at $20^{\circ} \mathrm{C}(\mathrm{g} / \mathrm{ml})$ & 1.320 & 1.312 & 1.326 \\
Ash at $900^{\circ} \mathrm{C}(\% \mathrm{~m} / \mathrm{m})$ & 0.12 & 0.17 & 0.16 \\
Coking value $(\% \mathrm{~m} / \mathrm{m})$ & 59.1 & 59.9 & 61.2 \\
Softening point $\left({ }^{\circ} \mathrm{C}\right)$ & 119.6 & 121.5 & 118.0 \\
Dynamic viscosity $170^{\circ} \mathrm{C}(\mathrm{MPa} \cdot \mathrm{s})$ & 1390 & 2070 & Not available \\
Ca $(\mathrm{ppm} \mathrm{m} / \mathrm{m})$ & 34 & 27 & 96 \\
Fe $(\mathrm{ppm} \mathrm{m} / \mathrm{m})$ & 192 & 101 & 153 \\
$\mathrm{Na}(\mathrm{ppm} \mathrm{m} / \mathrm{m})$ & 111 & 130 & 100 \\
Pb $(\mathrm{ppm} \mathrm{m} / \mathrm{m})$ & 144 & 176 & 147 \\
$\mathrm{~S}(\% \mathrm{~m} / \mathrm{m})$ & 0.47 & 0.17 & 0.58 \\
Si $(\mathrm{ppm} \mathrm{m} / \mathrm{m})$ & 132 & 94 & 250 \\
$\mathrm{Zn}(\mathrm{ppm} \mathrm{m} / \mathrm{m})$ & 241 & 202 & 197 \\
\hline
\end{tabular}

The biomass materials used in this study and the conditions used during the bio-coke manufacturing process (pyrolysis and calcinations) are summarized in Table 2. One pyrolysed bio-coke sample as received from Boisaco Inc. was studied (No. 1 as shown in Table 2). The pyrolysed (uncalcined) bio-coke was obtained from softwood trees at the maximum temperature of $426^{\circ} \mathrm{C}$; other information on heat treatment is not available. The calcined bio-coke samples (No. 2 in Table 2) were obtained by calcining the pyrolysed bio-coke at University of 
Quebec at Chicoutimi (UQAC) laboratory using an induction furnace. Details of calcination are presented in Section 2.2. Specimens for the experimental study were arbitrarily selected for a complete statistical randomization. They were stored in a room at $20^{\circ} \mathrm{C}$ and $40 \%$ relative humidity. The characterization tests are described below.

Table 2 Conditions of manufacturing process

\begin{tabular}{cccccccc}
\hline Sample & $\begin{array}{c}\text { Raw material } \\
\text { sample }\end{array}$ & Start material & $\begin{array}{c}\text { Temp } \\
\left({ }^{\circ} \mathrm{C}\right)\end{array}$ & $\begin{array}{c}\text { Heating } \\
\text { rate } \\
\left({ }^{\circ} \mathrm{C} / \mathrm{min}\right)\end{array}$ & $\begin{array}{c}\text { Holding } \\
\text { Time } \\
(\mathrm{min})\end{array}$ & Furnace & $\begin{array}{c}\text { Weight } \\
\text { lose } \\
(\%)\end{array}$ \\
\hline 1 & $\begin{array}{c}\text { Uncalcined } \\
\text { bio-coke }\end{array}$ & Softwood & 426 & - & - & Boisaco & \\
2 & $\begin{array}{c}\text { Calcined bio- } \\
\text { coke }\end{array}$ & $\begin{array}{c}\text { Boisaco bio- } \\
\text { coke }\end{array}$ & 1200 & 40 & 15 & $\begin{array}{c}\text { UGAC- } \\
\text { TGA }\end{array}$ & \\
& & & & & & & \\
induction & 58.8 \\
\hline
\end{tabular}

\subsection{Calcination of bio-coke}

The bio-coke samples received from Boisaco Inc. were heat treated (calcined) in a Thermogravimetric Analyser (TGA) using induction heating at UQAC, Quebec, Canada. Treatment temperatures and heating rates, which are typically used for petroleum coke calcination, were used during bio-coke calcination tests. During calcination of petroleum coke, volatiles are released and the crystalline length is increased. The green anodes, which are made of calcined petroleum coke and coal tar pitch, are baked in horizontal anode baking furnaces up to $1000^{\circ} \mathrm{C}$ to $1200^{\circ} \mathrm{C}$ to produce baked anodes. If the coke is not previously calcined at high temperature, it will still go through a structural modification and devolatilization during anode baking which might cause pore formation, thus, decrease the final anode quality. Since the original bio-coke samples were produced at $426^{\circ} \mathrm{C}$, the objective was to investigate the effect of calcination of bio-coke under the similar conditions to those of the petroleum coke calcination on its interaction with pitches. The bio-coke sample was put in a graphite crucible which was suspended from a balance to follow the weight loss of sample during calcination. The nitrogen, used as protection gas, enters the induction furnace from the bottom. The maximum calcination temperature of $1200^{\circ} \mathrm{C}$, the heating rate of $40^{\circ} \mathrm{C} / \mathrm{min}$ and $15 \mathrm{~min}$ of holding time at maximum temperature were used.

\subsection{Sample characterization}

\subsubsection{Wetting tests}

The contact angles between pitch and bio-coke were determined using a sessile-drop experimental system [31]. This system consists of a tube furnace (Thermolyne 21100), an inconel tube with a pitch injection system, a graphite sample crucible, a digital video camera (B/W) (APPRO, model KC), and a secondary rotary vacuum pump (GE, Precision Vacuum Pump, Model D25). Bio-coke powder was placed in a graphite sample crucible. The metal injection chamber holds the solid pitch sample. This chamber has a small hole at the bottom and was placed just above the coke bed during the experiment. The details of the experimental system is given elsewhere [28].

In this study, three coal tar pitch samples and two bio-coke samples (pyrolysed and calcined) were tested. According to literature [20], coke particle sizes between $100 \mu \mathrm{m}$ and $200 \mu \mathrm{m}$ were found to be suitable to study the wettability of a granular solid by a liquid. Accordingly, bio-coke particles were ground and an average particle size of 100-125 microns was used for the wetting tests. The particles were compacted in the sample crucible in order to have smooth bio-coke bed surface. A known amount of pitch was ground and put in the injection chamber, which was then positioned above the bio-coke sample. When the furnace was heated to the desired temperature $\left(170^{\circ} \mathrm{C}\right)$, the molten pitch droplet was directly placed on bio-coke substrate by arranging the position of the injection chamber hole. The drop size can be changed by adjusting the pressure difference between the inside and outside of the chamber. The sample holder can be removed from the hot region of the furnace by using the specially designed mechanism and the droplet sample were collected for further analysis. The system uses video image processing which makes the faster determination of dynamic contact angles possible compared to the conventional contact angle goniometry. The initial period after trigger was $0.033 \mathrm{~s}$ and the post-trigger period multiplier was set up to 1.2. A video of the drop was captured for 25 minutes. The system can capture both static and dynamic images. The FTA 32 software was used to measure the contact angle. In order to decrease the $\mathrm{O}_{2}$ and humidity content of the $\mathrm{N}_{2}$, it was passed through $\mathrm{O}_{2}$ (Chromatographic Specialties, Oxygen Trap C36084) and humidity traps (Chromatographic Specialties, Glass Moisture Trap - C36150) before it entered the system. Two or three tests were performed for each set of experimental conditions. The contact angles between each droplet and specimen surface were measured both on the left side and the right side of the droplet and the mean contact angles were automatically calculated. The dynamic contact angle data were used to assess wettability of the bio-coke. To compare the wettability of different bio-cokes by pitches, their initial 
contact angles and K-values were determined [31] by curve-fitting the experimental data to Eq. (1) using a nonlinear method.

$$
\theta=\frac{\theta_{i} \theta_{e}}{\theta_{i}+\left(\theta_{e}-\theta_{i}\right) \exp \left(K\left(\frac{\theta_{e}}{\theta_{e}-\theta_{i}}\right) t\right)}
$$

where: $\theta$ is the contact angle measured at time $t, \theta_{i}$ is the initial contact angle, $\theta_{e}$ is the apparent equilibrium contact angle, and $\mathrm{K}$ is the penetration and spreading rate constant. The total time of wetting can vary significantly from sample to sample. Therefore, the apparent equilibrium contact angle $\theta_{\mathrm{e}}$ was determined as the contact angle measured at an arbitrarily chosen time after the drop is deposited on the coke bed for all the samples. This approximation permits the identification of the wettability trend and allows the comparison of the results for different samples [31]. The contact angle measured at $200 \mathrm{~s}$ was used as the apparent equilibrium angle in Eq. (1) in order to solve for the K-value. If the measured apparent $\theta_{e}$ is zero, a contact angle of 0.01 was used in Eq. (1). K-value represents how fast the liquid pitch spreads and penetrates into the porous structure of bio-coke. Higher K-value indicates that the contact angle reaches equilibrium more rapidly and the liquid penetrates and spreads faster (increased wetting).

\subsubsection{Optical microscopy}

Epoxy liquid resin was chosen for the preparation of polished sample blocks at room temperature [12] for both bio-coke and pitch samples as well as sections of solidified drops from the sessile drop tests (pitch/bio-coke interface) for characterization with optical microscope. Polishing was carried out using Struers polisher to create a scratch free surface. Afterwards, a Nikon Eclipse ME600 optical microscope (Nikon Inc., Melville, NY) with a magnification of $1000 \times$ was used to analyze the morphology of the samples. Composite images were obtained from the digital camera attached to the microscope and operated with Optical Image Analyzer (Clemex JS2000). The optical analysis of polished blocks provides sectioned images of the internal structure of the cokes and solids present in pitch on the interface of pitch/bio-coke drops.

\subsubsection{SEM/EDS microscopy}

To prepare bio-coke sample surfaces for SEM, all small unpolished bio-coke samples were mounted onto an aluminum block surface with dimensions of $20 \times 30 \mathrm{~mm}$ using electrically conducting paste. The test pieces were cleaned with high pressure dust-removing gas to remove surface debris and to provide stronger attachment of bio-coke particles to the electrically conducting paste. The polished blocks of pitch and pitch/bio-coke interface in sessile drop used for optical microscopy analysis were also used as is for SEM analysis. For electrical conduction, all samples of bio-coke, pitch and drop sections were sputter-coated for $140 \mathrm{~s}$ with a palladium/gold layer (around $20 \mathrm{~nm}$ ) and then mounted onto standard aluminum stubs using electrically conducting paste. The samples were scanned using a Jeol scanning electron microscope (JSM 6480LV) at an accelerating voltage of $10 \mathrm{kV}$. Electron micrographs of surfaces on different directions for bio-cokes as well as those of pitches were taken. SEM micrographs of cross-section surfaces of pitch/bio-coke drops obtained from wetting tests were also taken to investigate the interaction at the interface. Energy dispersive X-ray spectroscopy (EDS) was used as an analytical technique for the oxygen and nitrogen content analysis of bio-coke samples before and after calcination.

\subsubsection{FTIR spectroscopy}

Infrared spectroscopy is a highly useful tool for obtaining rapid information on the chemical structure of materials. The FTIR spectrometer has been used for surface characterization to estimate the carbohydrate contents in biomass materials [32-42]. In this study, the chemical structures of bio-coke and pitch samples were examined by FTIR spectroscopy at room temperature. Chemical structure of pitch/bio-coke interface was also examined by FTIR analysis and it is compared with those of individual bio-coke and pitch in order to determine the modifications taking place during their contact. The main objective was to identify the new bond formation at the interface. IR spectra were collected in the wave number range of $400-4000 \mathrm{~cm}^{-1}$ and all the spectra were recorded at $4 \mathrm{~cm}^{-1}$ resolution. Each time, 20 scans were carried out prior to the Fourier transformation. All spectra were collected using a $\mathrm{KBr}$ technique (Perkin Elmer Instument, Spectrum one) and all the results were the average of two experiments. The samples were mixed with $\mathrm{KBr}$ at the ratio of $1: 100$. Then, the mixture was pressed to a pellet form for FTIR analysis. The effective depth of the surface scanning is 0.5-5 $\mu \mathrm{m}$. All spectra were analyzed using spectrum version 5.0.1 software. The IR spectra for each experimental set were transformed into absorbance spectra.

\subsubsection{X-ray diffraction}


The bio-coke samples obtained at $426^{\circ} \mathrm{C}$ and $1200^{\circ} \mathrm{C}$ were ground to a fine powder and characterized by X-ray diffraction using Bruker D8 Discover system and their Lc were obtained at $26.5^{\circ}$.

\subsubsection{Chemical element analysis}

Sulphur and carbon content determination of bio-coke samples was done in Earth's Materials Laboratory of UQAC (LabMaTer) with an EMIA-220V Induction furnace (Leco) from Horiba.

\section{Results and discussion}

\subsection{Wettability}

\subsubsection{Bio-coke wettability characterized by initial contact angle and total wetting time}

The initial contact angles, K-values and the times at which the complete wetting took place for bio-cokes before and after calcination for all three coal tar pitches are presented in Table 3. As it can be seen from this table, the values of initial contact angles of calcined bio-cokes were higher and their complete wetting times were longer than those of uncalcined bio-cokes for all the pitches studied. This result suggests that calcination reduces the wettability of bio-coke by pitch; consequently, it increases initial contact angle and total wetting time. This is in agreement with the results of previous study on petroleum coke [21], which explains that the heat treatment results in distillation and polymerization of coke and consequently the reduction in affinity of pitch for coke. The differences in initial contact angle for uncalcined bio-coke with different pitches are not significant, while they exhibit different total wetting times, ranging from 339.7 s for pitch-1 to $1036.9 \mathrm{~s}$ for pitch-3. The initial contact angle for calcined bio-coke with pitch-1 and pitch-2 are remarkably similar to each other but significantly higher than that of pitch-3. However, the total wetting time needed with pitch-2 and pitch-3 (>1600 s) are much longer than that with pitch-1(490. $7 \mathrm{~s})$. This result indicates that different pitches wet the same coke differently and the parameters characterizing the wetting phenomena are different.

Table 3 Summary of initial contact angle, K-value, total wetting time for complete surface wetting by different pitches on bio-coke before and after calcination

\begin{tabular}{cccccc}
\hline Sample & & $\begin{array}{c}\text { Initial contact } \\
\text { angles } \theta i\left(^{\circ}\right)\end{array}$ & $\begin{array}{c}\text { Total wetting } \\
\text { time (s) }\end{array}$ & K-value & $\mathrm{R}^{2}$ \\
\hline $\begin{array}{c}\text { Uncalcined } \\
\text { bio-coke }\end{array}$ & Pitch-1 & 80.09 & 339.7 & 0.0153 & 0.926 \\
& Pitch-2 & 78.16 & 713.7 & 0.0142 & 0.993 \\
Pitch-3 & 82.32 & 1036.9 & 0.006 & 0.939 \\
\hline balcined & Pitch-1 & 102.23 & 490.7 & 0.0144 & 0.850 \\
& Pitch-2 & 102.21 & $>1600$ & 0.0079 & 0.939 \\
\hline
\end{tabular}

where $\theta i$ : Initial contact angle; K-value: the spreading and penetration constant; $\mathrm{R}^{2}$ : correlation coefficients

It seems that taking in to account initial as well as dynamic contact angles, and the K-value leads to a more complete characterization of wetting instead of using each of these parameters separately [31].

\subsubsection{Bio-coke wettability characterized by K-value}

Spreading and penetration for a given pitch/coke pair can be characterized by determining their K-value. The model expressed in Equation (1) was used to determine the K-value. Higher K-value indicates that the contact angle reaches equilibrium more rapidly and the pitch flows and spreads faster into bio-coke bed. In other words, higher K-value means increased penetration and better wetting. Table 3 also summarizes the K-values and their correlation coefficients $\left(\mathrm{R}^{2}\right)$ for the bio-cokes before and after calcination with three different pitches. $\mathrm{R}^{2}$ values of the wetting model are over 0.926 for all of the samples examined except for pitch-1 $(0.850)$. $R^{2}$ is the measure of the fit quality, and high value indicates that the wetting data fits the cited model well. The K-values of the uncalcined bio-cokes are higher than those of the calcined bio-cokes for all three pitches but to different extents. This means pitches in this study have better spreading and penetration ability on the uncalcined bio-coke compared to the calcined bio-coke coming from the same source. These results also show that the changes in pitch spreading and penetration due to calcination depend on the pitch type. The K-value of pitch- 1 is the highest compared to the other two pitches for both bio-cokes. These results imply that pitch- 1 is the most suitable of the three pitches to be used in anode production.

3.1.3 Bio-coke wettability characterized by dynamic contact angle 
The dynamic contact angles of the wetting experiments were recorded for both bio-cokes before and after calcination for three different coal tar pitches.
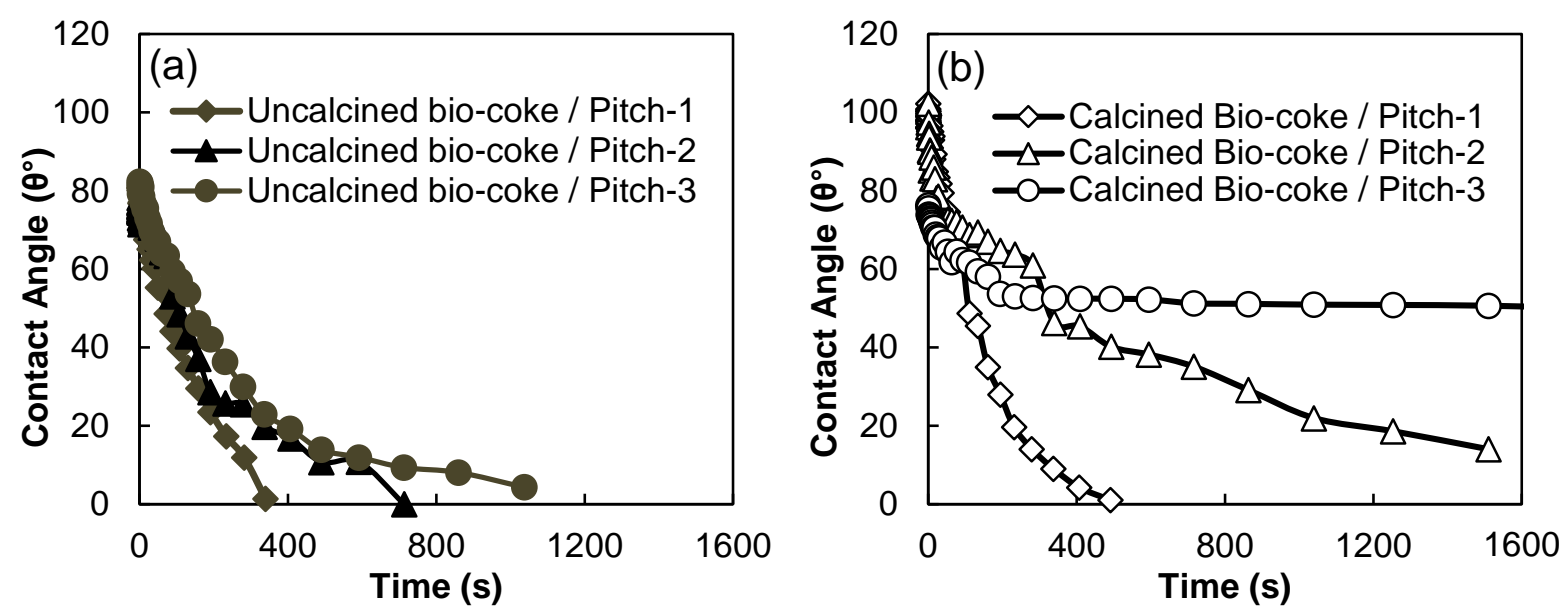

Fig. 1 Dynamic contact angle of different pitches (a) uncalcined (b) calcined bio-cokes

Figs. 1a and 1b present the dynamic contact angles as a function of time for three pitches on bio-coke before and after calcination, respectively. As shown in Fig. 1a for uncalcined bio-coke, the contact angles by three different pitches do not seem to differ significantly at the initial stage of wetting, whereas the difference increases with increasing time. The contact angle of pitch-1 is the smallest (best wetting) and that of pitch-3 is the highest (least wetting) at any given time. Consequently, the time needed for complete wetting, where contact angle reaches to zero, follows the same order (shortest for pitch-1 and longest for pitch-3).

However, the calcined bio-coke exhibit more complicated wetting behavior (see Fig. 1b). The results show that the order of contact angles for different pitches differ at different times. At initial times, the pitch- 1 and pitch- 2 have relatively high contact angles up to $100 \mathrm{~s}$, whereas pitch-3 exhibits lower contact angles. At longer times, contact angle of pitch- 1 reduces quickly to 0 at around 500s, while those for pitch- 2 and pitch- 3 continue to decrease slowly. After a certain time (about 200s), the contact angle for pitch-3 stays almost constant, which means the penetration and spreading of pitch-3 becomes very small at this time. As can be seen from the above results, calcined bio-coke is wetted better at the initial times by pitch-3 than pitch- 1 and pitch- 2 while the pitch1 penetrates faster than pitch- 2 and pitch- 3 when the wetting times increases. Therefore, the residence time of the industrial mixer is also important factor in suitable bio-coke/pitch pair selection.

Comparison of Figs. 1a and 1b shows that the high temperature calcination reduces the wettability of bio-cokes by pitch since all the contact angles of calcined bio-coke are found to be higher than those of uncalcined biocoke for the same pitch. The contact angle values obtained for three pitches on uncalcined coke are closer to each other compared to those on calcined bio-coke. The contact angles increase after calcination for all the three pitches at different extents depending on the pitch type. The differences in contact angles of uncalcined and calcined bio-cokes are significant for pitch- 1 and pitch-2 but small for pitch-3 at the initial stage of wetting (see Fig. 1a and b). At longer times, the difference is found to be the smallest for pitch- 1 . For pitch-2 and pitch-3, the difference continues to increase with increasing time.

The wetting behavior and penetration capacity of a pitch into bio-coke can be related to the nature of interaction between them, which is the basis of final electrode properties such as thermal and electrical properties, crushing strength, reactivity, etc. It was reported that the interaction between petroleum coke and pitch depends on the properties of pitch such as the quantity and nature of quinoline insolubles (QI), beta-resins and also on the properties of coke such as structure and porosity [20]. The mechanism of pitch/bio-coke interactions are studied and correlated with the physical and chemical properties of different coal tar pitches as well with those of uncalcined and calcined bio-cokes.

\subsection{Pitch/bio-coke interactions}

\subsubsection{Interactions characterized by optical microscope}

In order to investigate the influence of pitch composition and bio-coke structure on pitch/bio-coke interactions, considerable attention has been given to the associated microstructures of pitch and pitch/bio-coke interface. The optical microscopy images on the cross surfaces of droplets of three coal tar pitches on uncalcined and calcined bio-coke beds were taken (see Fig.2). The pitch and bio-coke particles can be easily identified from the optical microscopy images. 
Anisotropic and isotropic are two extremes of coke structure [16]. Anisotropic cokes have a coarse texture with essentially parallel arrangements of lamellae and their properties change with orientation [16, 43]. Anisotropic coke is weak to shear and cleavage of the basal planes. Besides, it has insufficient carbon edge-atom sites for chemical bonds at the pitch-coke interface with anisotropic contact surface [44]. The extremely anisotropic coke, which has a needle-like structure [43], is premium coke used in the ultra-high power electrode production [45]. However, if extremely anisotropic coke is used as raw material for anode production, the quality of anode deteriorates [44]. On the other hand, isotropic cokes are cokes with a fine grained texture and packed lamellae arranged almost randomly and show similar properties in all directions [16, 43]. They are harder than anisotropic coke and anodes formed with these cokes have better mechanical properties compared to those made with anisotropic cokes [16], but they can cause problems during grinding and crushing and result in higher dust formation. Thus, a controlled degree of crystallite disorder is necessary for coke. For filler cokes, fluid and delayed heterogeneous sponge-honeycomb structure cokes, which is a mixture of fine (isotropic) and coarse (anisotropic) textures, have been found to be disordered to the degree suitable for anode production and preferred by anode producers [43] [44]. It was reported previously that bio-cokes can be defined as more anisotropic than isotropic and their porosities are higher than those of petroleum coke [18]. These might contribute to the low density and consequently the low mechanical property of bio-coke. The porous structures of uncalcined bio-coke were broken down by grinding to small particle size of $100-125 \mu \mathrm{m}$ (see Fig.2a, c, e), which might enhance the density of bio-coke particles. This agrees with the study of Monsen and his co-workers [11] who suggested that the finer fractions of bio-coke should be used in carbon anode making. However, it can be seen from Fig. 2 (b, d, f) that the calcined bio-coke still possesses porous structure while those of uncalcined bio-cokes were destroyed and no obvious porous cell lumen can be observed ((Fig. 2 (a, c, d)) after a same grinding and crushing procedure. This might be due to its better strength as a result of the increase in the crystallite size influenced by the degree of calcination comparing to uncalcined coke [16]. However, more experimental work is needed to validate these results. Fig. 2 shows the appearance for both uncalcined and calcined bio-cokes as long strips differing in transverse and longitudinal direction. If the degree of isotropy is measured by the distribution of width to length ratio of bio-coke particles, defined as the particle width in transverse direction divided by the particle length in longitudinal direction, the width to length ratios for both uncalcined and calcined bio-cokes for the particle size used in this study were determined to be in the range of 0.3 to 0.6 , which is between the ratio of an anisotropic coke and an isotropic coke [46].The micrographs showed that there is a common occurrence in the microstructures of the three coal tar pitch droplets placed on bio-cokes (Fig. 2). The microstructure of pitch contains carbon solid particles (black areas) in an isotropic matrix (white background). The solid particles in pitch can be determined by dissolving the pitch in very good solvents such as quinoline, followed by their filtration [47]. These particles consist of true or primary QI and secondary QI or mesophase [47]. Primary QI is finely distributed in pitch and is small in size - average diameter corresponds to about $1 \mu \mathrm{m}$. Contrary to the primary QI, secondary QI or mesophase particles are about one to two orders of magnitude larger than primary QI [46]. The white matrix shown in Fig.2 is the soluble (or plastic) portion of pitch. It can be observed clearly from Fig. 2 (a-f) that the penetration and distribution of different components of different pitches are different in uncalcined and calcined bio-cokes. The three coal tar pitch droplets show different textures on bio-coke beds. The both components (solid particles and soluble portion) of pitch-1 penetrate completely into both bio-cokes particles. The solid part of this pitch (QI) is evenly distributed in biocokes. Pitch-1 seems to be the best binder pitch for both bio-cokes among the pitches studied. It can be observed from Fig.2 c, d, e, $\mathrm{f}$ that pitch-2 and pitch-3 do not show this even distribution but isotropic solid particles and anisotropic structures of pitch are separated and present separately in isolated large sections. The bio-coke bed acts as a filter for the soluble portion of pitch-2 and pitch-3 and, particularly, solid spherules remain at the surface of the bio-coke bed (see Fig.2 c, d, e, f). This is similar with the result for penetration of pitch on petroleum coke bed reported in the literature [19]. Some of the macromolecules form a network acting as a filter which absorbs other smaller molecules and form a smaller filter. The combination of these filters prevents part of soluble part from penetrating the bio-coke (see Fig. 2 e, f). This is responsible for the inferior wetting properties of pitch-2 and pitch-3 on bio-coke beds compared to those of pitch-1. It can be observed that the widths of QI sieve are different for pitch-2 and pitch-3 on uncalcined and calcined bio-coke (see Fig.2 c, d, e, and f). The sieve effect of pitch-3 is stronger than that of pitch-2 for both bio-cokes; however, these effects are stronger on calcined bio-coke than uncalcined bio-coke for the same pitch. The penetration characteristics of different pitches on bio-coke are related to wettability and they are in agreement with the contact angle results presented in the previous section. 

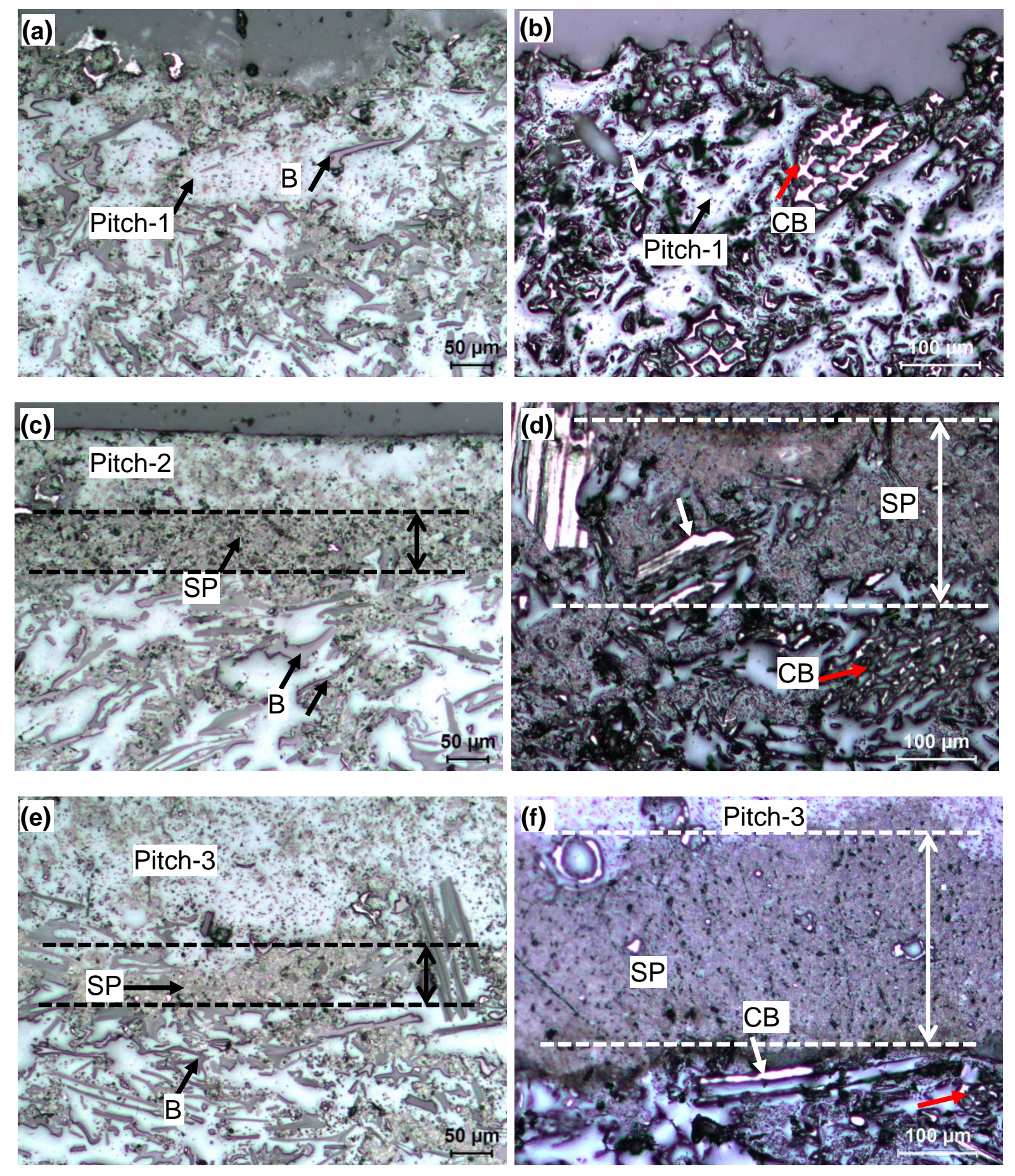

Fig. 2 Optical micrographs on cross-section of pitch drops on bio-coke beds: (a) B/Pitch-1, (b) CB/ Pitch-1, (c) B/ Pitch-2, (d) CB/ Pitch-2, (e) B/ Pitch-3, (f) CB/ Pitch-3

(B: uncalcined bio-coke, CB: calcined bio-coke, SP: solid particle)

The textures of three typical coal tar pitches with different QI contents (see Table 1) are shown in Figure 3. The microstructure consists of islands or networks of carbon solid particles (black areas) in an isotropic matrix (white background), which is the soluble (or plastic) portion of pitch. The optical microscope can be employed to carry out a size count for solid particles present in pitch [48]. Typical fine grain containing isotropic clusters are clearly observed in the micrograph of the pitch. The concentration of these clusters depends on the concentration of QI (see Fig. 3 (a-c)). Pitch-3 in Fig. 3c shows the highest concentration of solid particles, followed by pitch-2 in Fig. 3b and finally by pitch-1 in Fig. 3a. This is in agreement with the QI contents of pitches summarized in Table 1. 


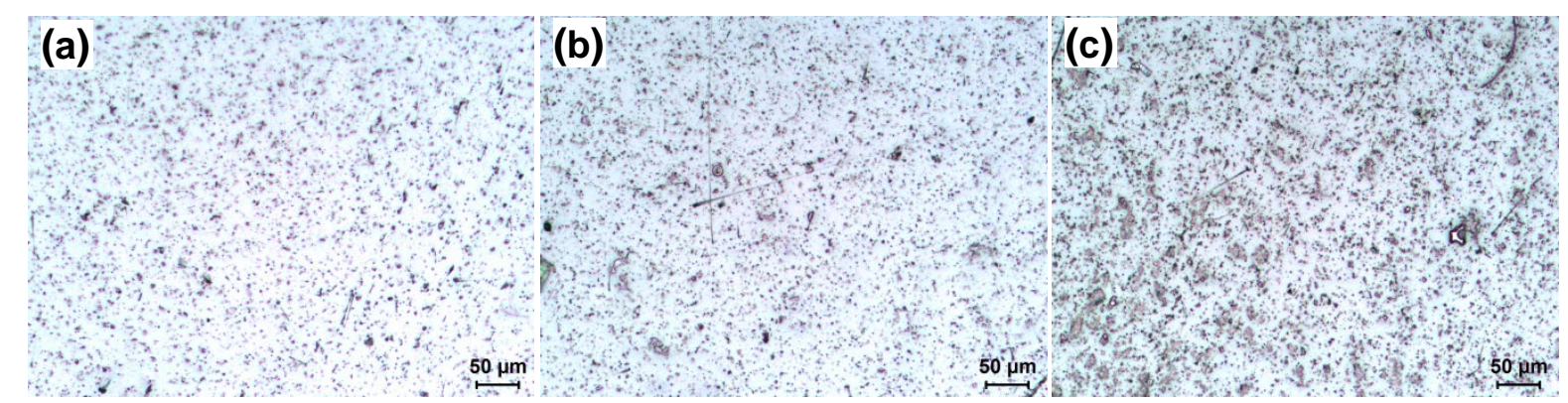

Fig.3 Optical micrographs of pitches: (a) pitch-1, (b) pitch-2, (c) pitch-3

The effect of QI content in coal tar pitches on K-value for uncalcined and calcined bio-coke is shown in Fig.4. It can be observed that the calcination temperature of the bio-coke changes the wettability of a bio-coke by a pitch. After calcination, the K-value of bio-coke decreases for all three coal tar pitches. It might be due to the fact that the bio-coke surface is more carbonized and the crystallites tend to align themselves more perfectly, which make the calcined bio-coke more difficult to wet, and thus the K-value at the same wetting temperature decreases with calcination. This is similar to the effect of calcination on wettability of petroleum coke [22]. It was also reported that high temperature treatment has a significant influence on the structural properties of petroleum coke, and consequently, on the wettability of this coke by pitch [21, 27].

The different content of QI seems to influence the wetting properties of bio-coke by pitch. For both uncalcined and calcined bio-coke, the K-value decreases with the increasing QI content. This means that the presence of QI particles in pitch reduces the wetting and penetration capacity of the pitch. This might be due to several reasons. Firstly, QI particles do not contribute to wetting and thus reduce the effective pitch content which wets the coke [49]. Secondly, they need binder for their own wetting, hence, consume part of the available pitch. Larger QI particles need even more pitch to be wetted, because of their large specific surface in contrast to primary particles with a larger size. In addition, they deposit on the surface of the bio-coke and act like a sieve as shown in Fig.2 (c-f) which prevents the pitch from penetrating into the bio-coke and influences the wetting by changing the character of the bio-coke surface. Besides, the QI particles decrease the surface tension of the pitch due to the partial saturation of unbalanced forces at the surface of the liquid pitch at high temperature [47]. Decrease in surface tension should increase wetting. However, increasing QI increases also pitch viscosity [47] as can be seen in Table 1 . High viscosity decreases the wettability of coke by pitch. Pitch wetting behavior is defined by combined effect of surface tension and viscosity [25]. Therefore, increase in QI might have larger influence on the viscosity (increase) than on the surface tension (decrease) of pitch, and consequently, it reduces the wettability of bio-coke by pitch.

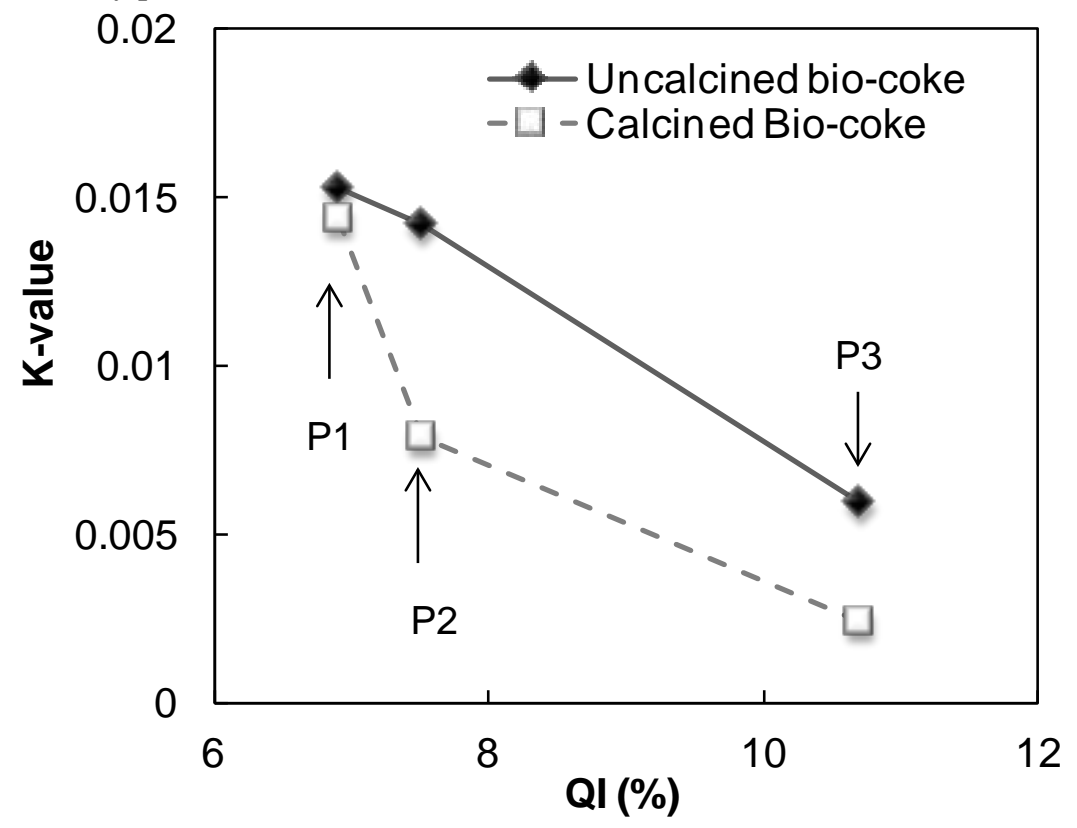

Fig.4 Effect of QI content in coal tar pitch on K-value for uncalcined and calcined bio-coke

3.2.2. Interactions characterized by SEM 
Optical microscope cannot offer more specific information on the bio-coke/pitch interactions. It is quite difficult to observe the structure of pitches with regards to the size of solid particles on the photo-micrographs with the magnification of optical microscope (Fig.3). Size of some of the small solid particles present in pitch is probably below the limit of optical microscope resolution and, therefore, not detectable by this procedure. More precise examination of the solid particles in pitch/bio-coke interface requires higher magnification than that obtainable with the optical microscope. The penetration phenomena of pitch into bio-coke can be better observed if the scanning electron microscope (SEM) is used for the observation of the droplet sample on its cross-sectional surface.

SEM is well suited to such a study due to its large depth of focus. It is possible to view directly the 3-D nature of solid particles in pitch matrix. SEM micrographs illustrating the appearance of three coal tar pitches at high magnification $(\times 10000)$ are shown in Fig. 5. At this high magnification, differences in the morphology of particles in different pitches can be detected. As shown in Fig. 5a, most of the solid particles of pitch-1 appear as individual spheres which are evenly distributed in the pitch structure. Solid particles in pitch-3 exhibit as bigger individual spheres than those in pitch-1 (Fig. 5c). The different solid particle sizes are mixed in pitch-2, and some of them have agglomerated to form clusters (Fig. 5b). Solid particles of pitch-2 (Fig. 5b) and pitch-3 (Fig. 5c) are larger than those of pitch-1 but their sizes are still smaller than $1 \mu \mathrm{m}$. It was documented that primary QI is produced by thermal cracking and incomplete combustion of volatile components liberated during the coking process form spheres which are less than $2 \mu \mathrm{m}$ in size [49]. Secondary QI, formed by polymerization of aromatic molecules in pitches at elevated temperatures, is normally larger than primary QI particles. The SEM observation results indicate that the three coal tar pitches in this study contain no observable mesophase spherules ( $1 \mu \mathrm{m}$ diameter), though pitches-2 and-3 have high solid particle content. The solid particles can be identified as primary QI. Pitch-1 is a more “typical” anode pitch, whose big size QI particles content constitutes only a minor part of the total QI fraction.

The QI content and particle size distribution can influence the wetting capacity of pitch. Bigger particles need more soluble resin in pitch to be wetted and they are easier to deposit on the surface of the bio-coke and prevent the soluble portion and other smaller particles in the pitch from penetrating into the bio-coke. These effects can be observed from the SEM images of droplet as shown below.
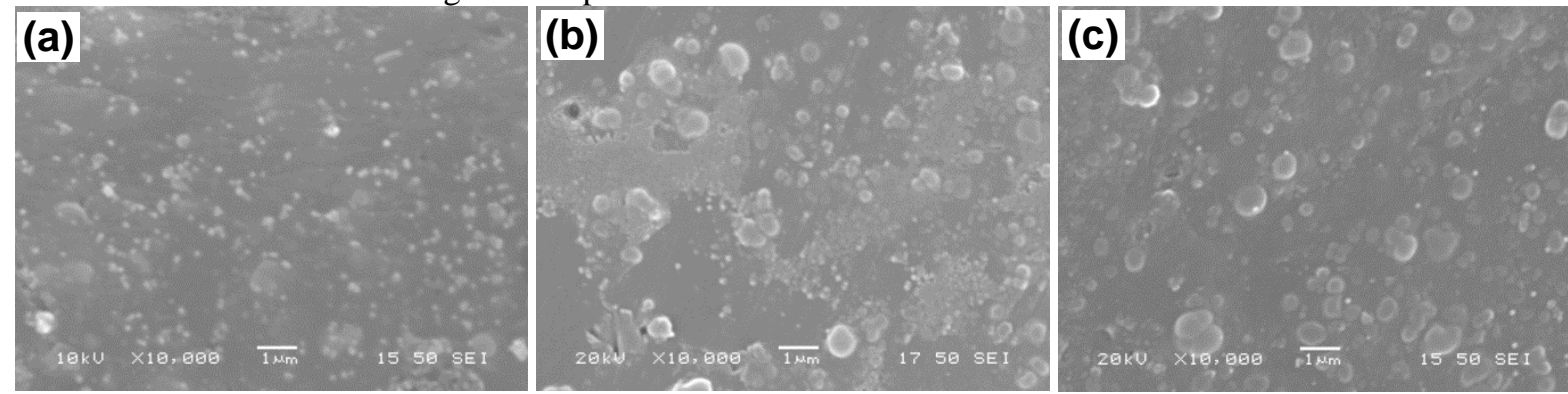

Fig.5 SEM micrographs of different pitches and QI particles (a) pitch-1, (b) pitch-2, (c) pitch-3

In order to examine the mechanisms of pitch/bio-coke interactions in more detail, pitch/bio-coke interface is studied using SEM at the magnifications of $\times 1000, \times 2000$, and $\times 4000$ (Fig. 6 (a-i)). Different aspects of pitch/bio-coke interactions at the interface can be characterized by means of this technique. Figs. 6 (a-c) are the SEM images of the structures on the cross section of the investigated pitch-1 droplets on uncalcinced bio-coke at different magnifications.

From Fig. 6, it can be observed that the microstructure morphology of uncalcined and calcined bio-cokes includes some long chip formations, with the width in the range of $3 \mu \mathrm{m}$, regularly dispersed on the continuous pitch matrix in horizontal direction layer by layer, forming a filter. It can be observed that all the components including QI particles and soluble portion of pitch-1 can penetrate evenly into the uncalcined bio-coke bed (Fig. 6 (a-b)). The soluble portion of pitch-1 wets well uncalcined bio-coke (see arrow in Fig. 6c) and the QI particle are distributed evenly in the soluble portion matrix around the bio-coke particle. This indicates good interaction between pitch-1 and uncalcined bio-coke. However, pitch-2 and pitch-3 do not properly penetrate into the uncalcined bio-coke substrate (see Fig.6 (d-i)). The contact between soluble portions of pitch-2 or pitch-3 and uncalcined bio-coke is not continuous. The cracks present between them (see arrows in Fig.6 (f, i)) imply an inferior connection and less interaction between soluble portions and bio-coke for pitch-2 and pitch-3 compared to those of pitch-1. This phenomenon is more pronounced for pitch-3 evident from the presence of more cracks observed from the SEM images (see Fig. 6h). The movement of QI particles through the uncalcined bio-coke particles is blocked for pitch-2 (see Fig. 6f) and pitch-3 (see Fig. 6h). As a result, the QI particles and the rest of the pitch are separated and layered. Also, the agglomeration of QI particles might reduce the wettability of biocoke and create cracks due to the differences in shrinkage of different components of pitch during cooling. 

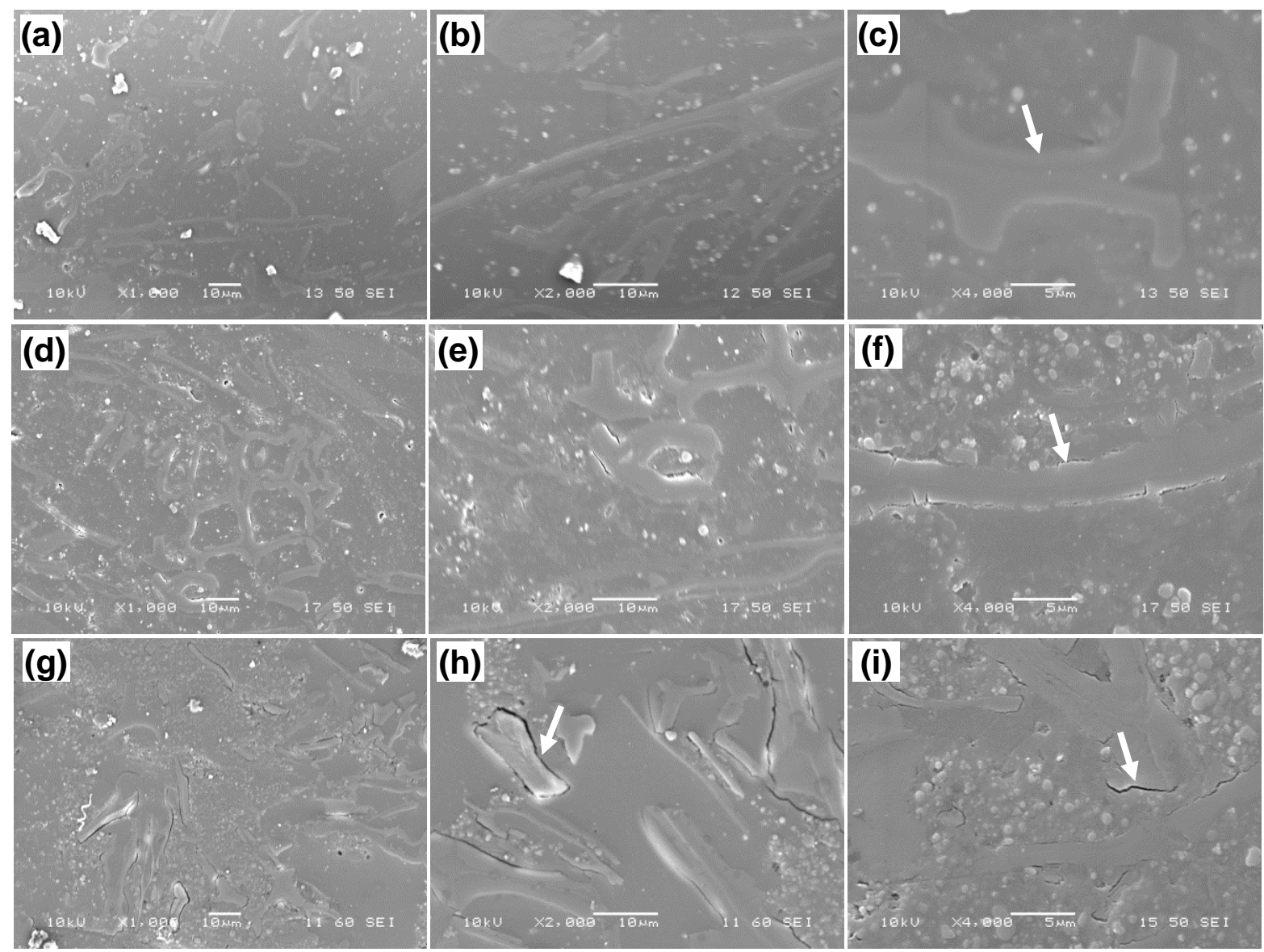

Fig.6 SEM micrographs of uncalcined bio-coke interface with different pitches (a-c) pitch-1, (d-f) pitch-2, (g-i) pitch-3 at different magnifications

The examination of cross section of calcined bio-coke/pitch interface is also carried out since complementary information can be withdrawn for calcined bio-coke (Fig. 7 (a-i)). Pore structures of calcined bio-coke particles can be seen clearly after it was in contact with three pitches in Fig. 7. The diameter of pores in bio-coke after calcination seems to be bigger than those of bio-coke before calcination (Fig. 6e and Fig. 7e). The bigger dimension of pore was expected to increase the pitch penetration into the cell, and consequently contribute to better calcined bio-coke wettability by pitch compared to that of uncalcined bio-coke. However, the experimental wetting results showed that the tendency is the opposite. QI particles cannot infiltrate into the porous structure of calcined bio-coke. They stay at its surface. This might explain the lower wettability of biocoke after calcination. It has been reported that a high content of soluble portion may alter the flow properties of a pitch [19]. The soluble portion (anisotropic matrix) flows easily into the pore system of bio-coke and fills completely the pore and then forms strong bond without forming cracks (see Fig. 7 (c,f,i)). This might result in low density and high pitch utilization which are considered as disadvantages. Porous bio-coke will need extra pitch binder as the binder will penetrate deep into the pores. Carbonized pitch has a much lower strength than the coke itself. Therefore, too much pitch is not appropriate. This can again influence the strength of the cokepitch bond and final anode properties. In addition, using more pitch increases the cost. The flow and infiltration of smaller QI particles of pitch-2 and pitch-3 through calcined bio-coke are prevented by bigger QI particles which act as a filter (Fig.7 (d and g)). The anisotropic matrix of pitch without reinforcing QI particles shrinks more due to its excessive plasticity during carbonization (baking) and consequently forms cracks/pores and often disbands from the filler bio-coke [46]. The QI particles penetrating into the spaces of the structure of filler reduce the effective thickness of the binder coke, consequently reinforce the liquid pitch binder and increase mechanical properties of composite anode [46]. Therefore, the QI penetrating into the space structure of biocoke will improve the performance of bio-anode. It can also be concluded from the results that the size of QI particle in pitch influences the penetration capacity of QI more than the amount of QI particles present. 

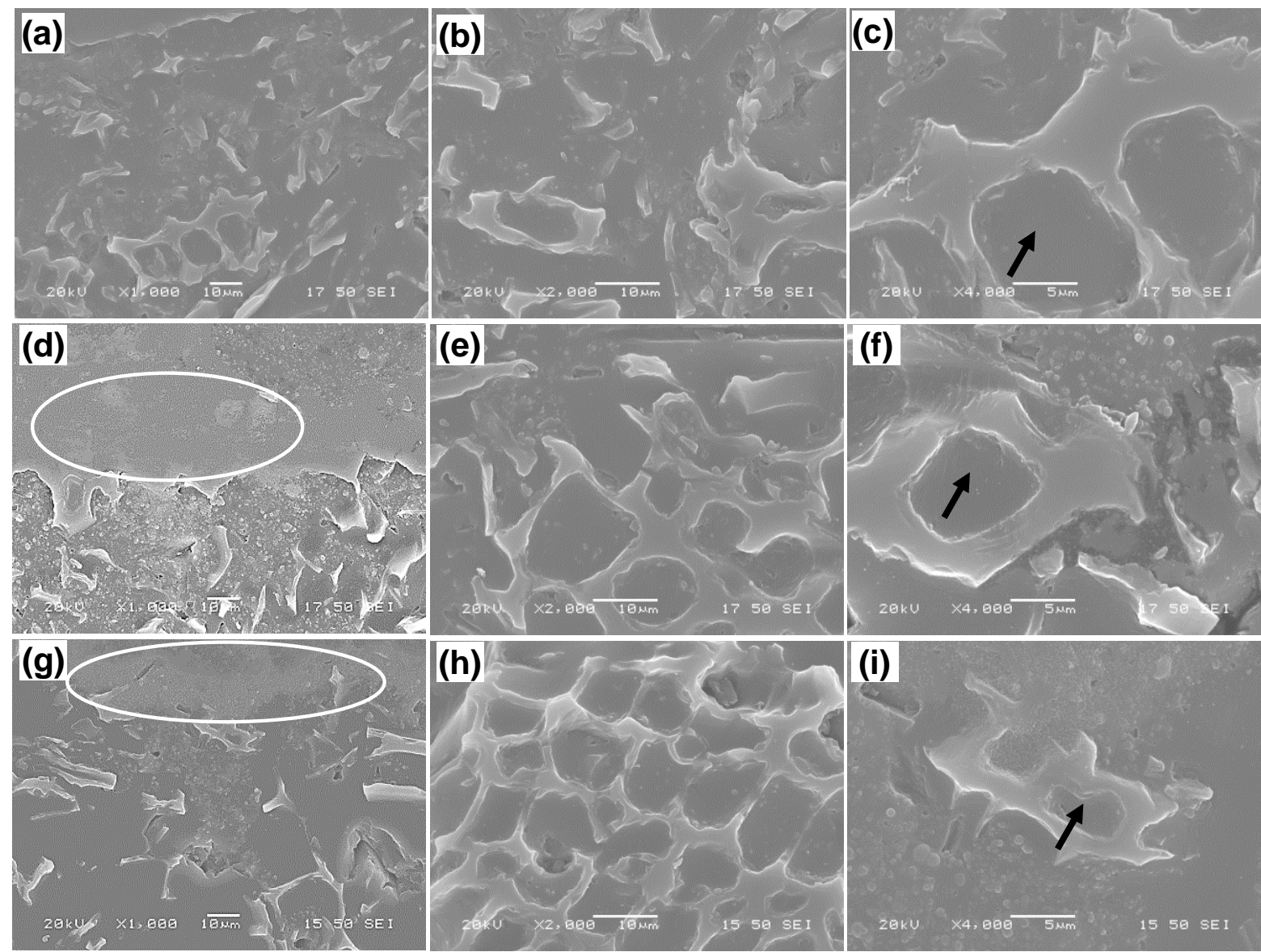

Fig.7 SEM micrographs of calcined bio-coke interface with different pitches (a-c) pitch-1, (d-f) pitch-2, (g-i) pitch-3 at different magnifications

(Arrows represent the soluble portion, ellipses represent accumulation of particles)

The maximum temperature of calcination has a strong influence on the pore structure, surface area, and adsorption properties of the bio-coke [10]. It was found that microporosity was established near $500^{\circ} \mathrm{C}$ and further heating volatilized residual material that blocked micropores [50], thereby increasing the micropore volume [51]. When the calcination temperature was increased up to $900^{\circ} \mathrm{C}$, shrinkage of the micropore structure was observed, which led to reduction in open porosity [50]. Thermal annealing at high temperature of uncalcined bio-coke results in loss of free sites, defects, and edges [52]. Corroborating these findings, the affinity of pitch with calcined bio-coke is reduced partly due to the reduction of open porosity, surface area and free sites.

It was reported in the literature that high temperature calcination induces changes not only in structural properties of a petroleum coke but also in its chemical properties [21]. Calcination might provoke similar changes in bio-coke. The penetration of the liquid pitch into coke bed depends on several parameters: the structure of coke; the size of the droplet; the physico-chemical properties of the pitch; and the physico-chemical properties of the interface [19]. Working with a constant droplet size and with a given granular bio-coke, it is possible to relate the flow behavior of a pitch to its chemical properties. The different chemical structures of pitches used might be the determining factors of pitch and bio-coke interactions. Therefore, the chemical characterizations of uncalcined and calcined bio-coke, different pitches, as well as the bio-coke/pitch interfaces were carried out using FTIR spectroscopy.

\subsubsection{Interactions characterized by FTIR spectroscopy}

The surface functional groups of uncalcined and calcined bio-cokes, three coal tar pitches as well as the pitch/bio-cokes interfaces were investigated using FTIR in order to study the effect of calcination on bio-coke composition, and subsequently on the wettability by different pitches. It should be mentioned that FTIR is a technique which is used to analyze surface chemistry; it is difficult to determine content of chemical component using this technique [31]. Therefore, the type of components should be quantified by other analysis techniques. In this study, each sample was tested two or three times and the average of these were used for spectrum analysis. The most representative bands for biomass, green petroleum coke and pitch within the spectral range of $4000-400 \mathrm{~cm}^{-1}$ are summarized in a previous study [53]. FTIR spectra of pure pitches at room temperature are shown in Fig. 8., Fig. 9 and Fig.11 show the FTIR spectra of uncalcined and calcined bio-coke before and after 
wetting experiments (contact) with different pitches. The functional groups on the surfaces of different coal tar pitches as well as uncalcined and calcined bio-cokes are summarized in Table 4.

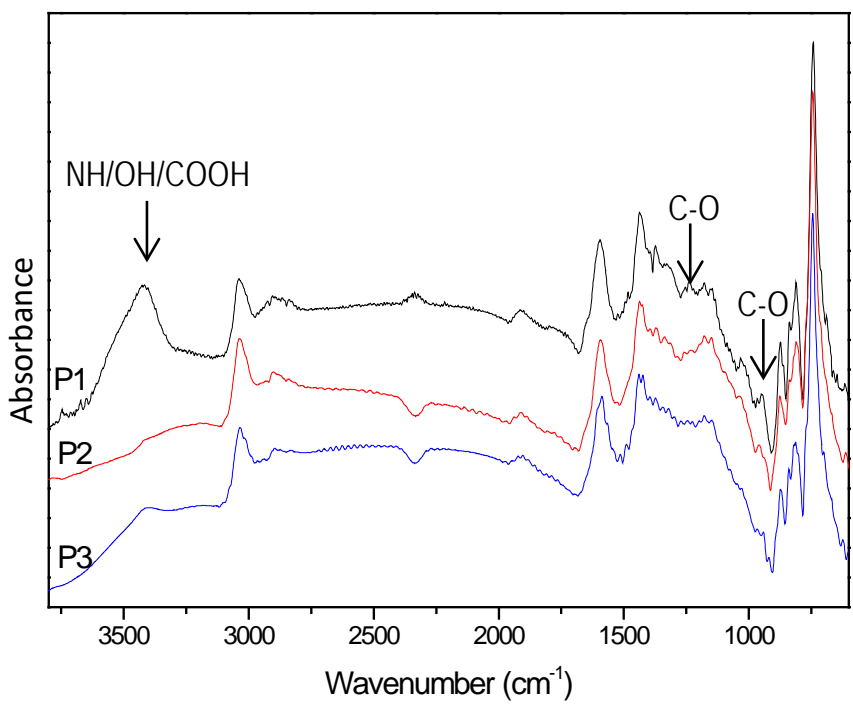

Fig.8 FTIR spectra of different coal tar pitches

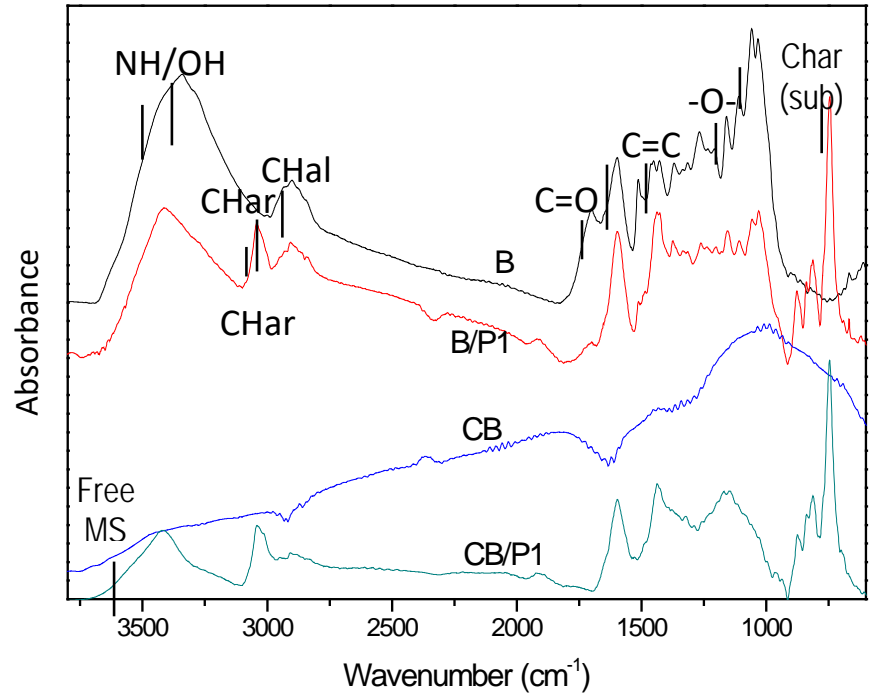

Fig.9 FTIR spectra of uncalcined bio-coke before(B) and after wetting experiment (B/P1), calcined bio-coke before (CB) and after wetting experiment (CB/P1)

(B: uncalcined bio-coke, CB: calcined bio-coke, P1: Pitch-1)

Table 4 - List of function group in different coal tar pitches as well as bio-cokes before and after calcination from FTIR study

\begin{tabular}{|c|c|c|c|c|c|c|c|}
\hline \multirow{2}{*}{ Line } & \multirow{2}{*}{$\begin{array}{c}\text { Wave } \\
\text { number } \\
\left(\mathrm{cm}^{-1}\right)\end{array}$} & Functional group & \multicolumn{2}{|c|}{ Cal tar pitch } & \multicolumn{3}{c|}{ Bio-coke } \\
\cline { 4 - 8 } & & Pitch-1 & Pitch-2 & Pitch-3 & $\begin{array}{c}\text { Uncalcined } \\
\text { bio-coke }\end{array}$ & $\begin{array}{c}\text { Calcined } \\
\text { bio-coke }\end{array}$ \\
\hline 1 & $3200-3500$ & NH /OH/ COOH & 2 & 0 & 1 & 2 & + \\
\hline 2 & $3000-3100$ & Aromatic C-H stretching & 2 & 2 & 2 & 2 & 0 \\
\hline 3 & $2800-2900$ & Aliphatic C-H & 2 & 2 & 2 & 2 & 0 \\
\hline 4 & 1799 & C=O & 2 & 2 & 2 & 0 & $2 *$ \\
\hline 5 & $1431-1505$ & $\begin{array}{c}\text { C=C Stretching } \\
\text { Vibrations }\end{array}$ & 1 & 1 & 1 & 2 & 0 \\
\hline 6 & 1126 & Esters C-O, ether, COOH & 2 & 2 & 2 & 2 & 0 \\
\hline 7 & $700-900$ & $\begin{array}{c}\text { Ortho-substitution of the } \\
\text { aromatic ring }\end{array}$ & 2 & 2 & 2 & 1 & 0 \\
\hline
\end{tabular}


where ' 2 ' means that the FTIR spectrum shows strong peak at the band, ' 1 ' means weak peak, ' 0 ' means that the peak of the FTIR spectrum at the band is not observed or not clear, '*' might be for $\mathrm{CO}_{2}$. ' + ' means diffused peak.

Three major interactions can be seen between the surface functional groups of bio-coke and pitch. The interactions are shown in Figure 10.

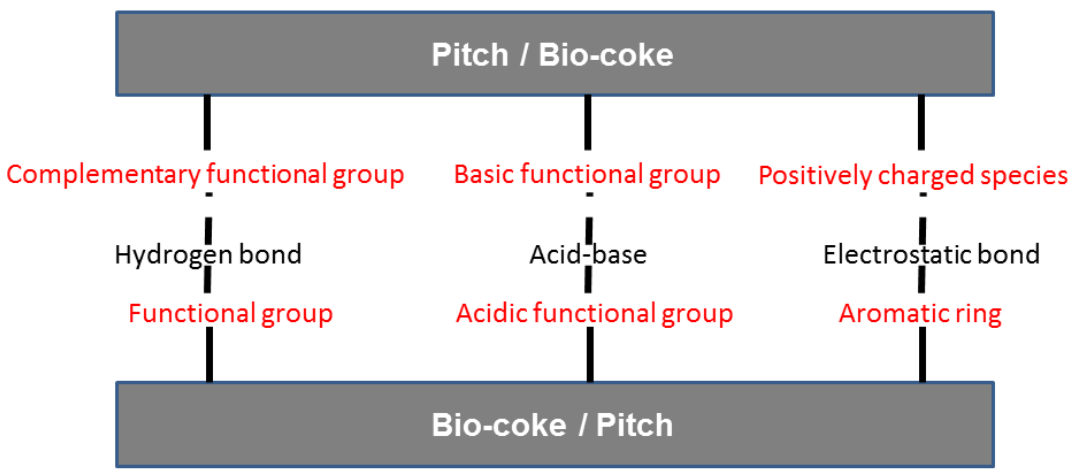

Fig. 10. Possible interactions between bio-coke and pitch

Hydrogen bonds are formed usually between hydrogen atom attached to a strongly electronegative atom (O or $\mathrm{N})$ and another electronegative atom $\left(\mathrm{O}\right.$ or $\mathrm{N}$ ). Thus $\mathrm{C}-\mathrm{OH}, \mathrm{C}=\mathrm{O}, \mathrm{NH}_{2}, \mathrm{COOH}$ can participate in the formation of hydrogen bonds. Acid-base interactions can take place between acidic functional groups such as $\mathrm{COOH}$, phenol, and basic functional groups such as $\mathrm{NH}_{2}$. Electrostatic interactions can take place between the pi electron cloud of aromatic rings and positive charged centers such as quaternary ammonium ion. To identify these interactions, the presence of different functional groups containing $\mathrm{O}$ and $\mathrm{N}$ atoms and aromatic rings were studied using FTIR. Table 4 shows the presence of those functional groups in bio-coke and pitch. The results show that there is a possibility of chemical interaction between the bio-coke and pitch samples. Sometimes the structure of molecules may change during the heating process. Presence of ortho-substitution in aromatic rings often might result in formation of cyclic compounds through condensation reactions.

The differences in spectra of bio-cokes before and after wetting experiments were taken into consideration to understand the interaction mechanism of pitch and bio-coke.

The surface functional groups such as $\mathrm{C}-\mathrm{OH}, \mathrm{COOH}$ and some alkyl groups of cokes play a key role in the chemical activation process [21]. As shown in Table 4, all the bands at 3500 3200, 1800, and $1100 \mathrm{~cm}^{-1}$ referring to heteroatom containing groups such as, amines (-NH), hydroxyl groups $(-\mathrm{OH})$, carboxyl groups ($\mathrm{COOH})$, carbonyl group $(\mathrm{C}=\mathrm{O})$, and $\mathrm{C}-\mathrm{O}$ group present on the uncalcined bio-coke surface and three coal tar pitches, help improve their interaction. As shown in Fig. 8 and 9, all these characteristic bands are stronger for uncalcined bio-cokes and pitch-1 than those of pitch-2 and 3. These results might explain the reason for the better wettability of uncalcined bio-coke by pitch-1 compared to those of other combinations (see Fig.1). Upon analysis of the spectra (Fig. 9), the results show that the surface chemical compositions of uncalcined and calcined bio-cokes are very different in nature compared to those of the pitch/bio-coke mixtures (spectra B/P1 and CB/P1 in Fig.9, respectively). The most significant differences due to the wetting by pitch are observed in the $2800-3200$ and $1500-1750 \mathrm{~cm}^{-1}$ region for both bio-cokes. These bands which show certain intensity in the calcined bio-coke/pitch mixture obtained after the wetting tests are not present in the unwetted calcined bio-coke samples (see Fig. 9 CB/P1 and CB). The intensity of these bands for uncalcined bio-coke increases after wetting by pitch (Fig. $9 \mathrm{~B}$ and $\mathrm{B} / \mathrm{P} 1$ ). These bands are corresponding to oxygen-containing functional groups that are formed during the wetting experiments via reactions involving aliphatic hydrogen [21]. The FTIR spectra in Fig. 9 show that bio-cokes are partially oxidized by pitch during their contact (wetting test). The spectra differences of calcined bio-coke before and after wetting are more evident than the case of uncalcined bio-coke. However, this cannot indicate if there is more reaction with calcined bio-coke or with uncalcined coke. The spectra of both uncalcined and calcined bio-coke become similar after contact with same pitch (see Fig. 9 B/P1 and CB/P1), but the intensity of the oxygen containing bonds are higher for uncalcined bio-coke than calcined bio-coke after wetting. The spectra show that uncalcined bio-coke has higher degree of aliphatic chains and heteroatom containing functional groups compared to those in calcined bio-coke. This fact can be indirectly related to the presence of higher amount of hydrogen in uncalcined bio-coke. This means that pitch interacts more intensively with uncalcined bio-coke which has higher hydrogen content and its interaction with calcined biocoke consists of less significant oxidation. This is in agreement with the literature which indicates that the cokes with lower hydrogen content do not go through any significant oxidation during wetting [21]. The FTIR spectra for uncalcined bio-coke consist of a small band near $3000 \mathrm{~cm}^{-1}$ due to aromatic C-H stretching vibrations. Presence of both aromatic rings and -OH groups $\left(3320 \mathrm{~cm}^{-1}\right)$ can indicate the presence of phenols which is 
acidic in nature. This acidic group in bio-coke might react with the basic amine $\left(-\mathrm{NH}_{2}\right)$ groups of pitch (3200$3500 \mathrm{~cm}^{-1}$ ). Therefore, the presence of phenols in uncalcined bio-coke is helpful for its interaction with pitch.

The different bio-cokes wetted by different pitches are similar to each other with regard to functionality; however, there were some qualitative as well as quantitative differences (see Fig. 11). Compared with the spectra of pitches (Fig. 8), the spectra of pitch /bio-coke mixtures show that several reactions take place during wetting experiments due to considerable decrease in intensity of adsorption bands at $1500-1750 \mathrm{~cm}^{-1}$ and increase in the absorbance in the region of $3200-3500 \mathrm{~cm}^{-1}$, which is indicative of significant changes in the content of oxygen structures during the wetting experiments. Significant diminution of the oxygen structure content in pitch takes place during the preparation of the anode composite [21]. The spectra of pitch/bio-coke mixtures confirm the possibility that the functional groups in the coal tar pitch may interact with the complimentary functional groups present on the bio-coke surface.

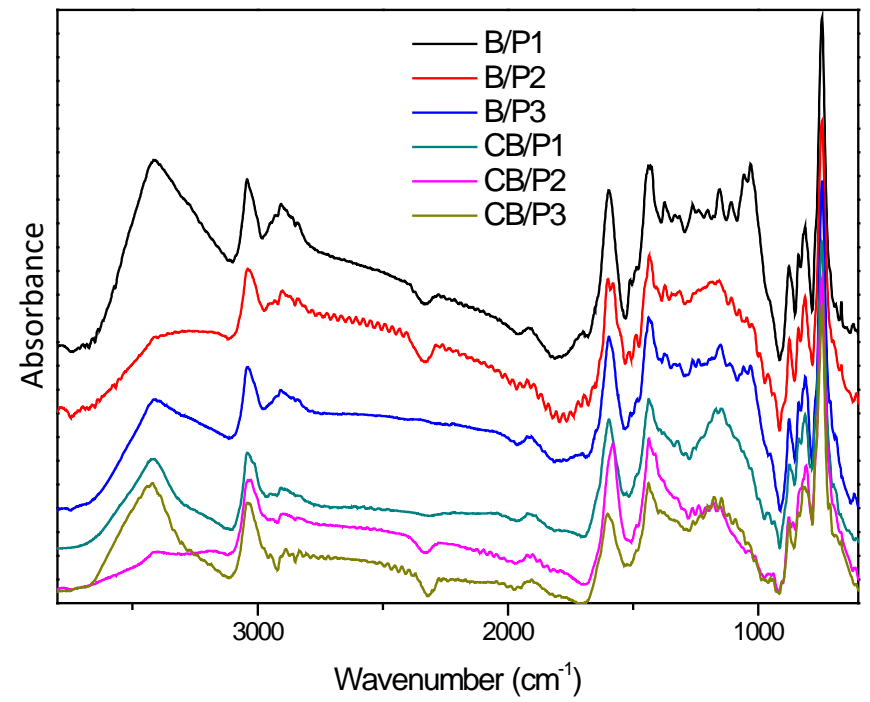

Fig. 11 FTIR spectra of uncalcined and calcined bio-cokes wetted with different coal tar pitches (P1: Pitch-1, P2: Pitch-2, P3: Pitch-3)

Strong peak ('2' shown in Table 4) of line \#1, \#4, and / or \#6 for pitch or bio-coke implies more chance of chemical interaction by hydrogen bond, covalent bond and condensation reactions. The presences of functional groups in these lines increase wettability of bio-coke by pitch. Label ' 2 ' in line \#2 indicates the presence of aromatic rings which have negatively charged pi electron cloud. These bonds form electrostatic bond with electron deficient centers. Consequently, presence of groups such as $\mathrm{NR}^{4+}$ also helps these interactions. Calcined bio-cokes do not contain significant amount of $\mathrm{N}$, therefore, presence of aromatic rings does not facilitate wetting. ' 2 ' in line \#3 and \# 7 indicates presence of aliphatic chains and substitution of aromatic rings. Free long aliphatic chains can offer steric hindrance to other reacting molecules and consequently inhibit wetting. Substitutions in branches might help in condensation reaction during calcination and also help cyclization reactions during mixing with pitch. The cyclization reactions during calcination increase fixed carbon content, which is one of the most important properties of bio-coke used as a raw material for anode making.

\subsubsection{Chemical element analysis and crystalline structure of bio-coke}

For a better understanding of the influence of chemical composition and microstructural changes, which are taking place during calcination of bio-coke, on the pitch/bio-coke interactions, availability of quantitative data on the chemical components and Lc of the uncalcined and calcined bio-cokes are invaluable. The carbon and sulfur content, and Lc of bio-cokes are summarized in Table 5. The results are discussed and compared with those of one petroleum coke.

Calcined bio-coke differs from uncalcined bio-coke, which is solid pyrolysis residue of organic material obtained at low temperature and without passing through a plastic phase. It can be seen that calcined bio-coke has higher C\% than that of uncalcined bio-coke. Calcined bio-coke is high-carbon, non-graphitic structure, and produced by carbonization which passes through a plastic phase (liquid crystalline or liquid) during the process of calcination. Calcination increases C\% of bio-coke to more than 99\%, which is higher than that of petroleum coke (93.2\%). The level of carbon content in uncalcined bio-coke is much lower than that of petroleum coke, which is a serious disadvantage in anode production and need to be improved by carrying out and optimizing the calcination process of bio-coke. However, increasing carbon content of bio-coke by calcination will decrease the wettability of pitch on bio-coke, which is another disadvantage for anode production. Therefore, it is important 
to find the conditions for producing bio-cokes which will be well wetted by pitch and will have high fixed carbon percentage. It can be observed from Table 5 that bio-cokes both before and after calcination have more oxygen and generally less sulfur content in their chemical composition than their petroleum-based counterparts. The higher amount of oxygen before calcination, which might make bio-coke more reactive (better biocoke/pitch interactions) compared to those of calcined bio-coke and petroleum coke. This is in agreement with the the FTIR results. Inorganic impurities also influence the pitch/bio-coke interaction (Table 1) [22]. Higher sulfur levels generally lead to increased expansion and hence degradation of final anode properties [54]. The level of sulfur in coke should be kept as low as possible for environment consistent with the manufacture of premium anode. Both uncalcined and calcined bio-cokes have low sulfur content. However, it is necessary to have a certain amount of sulfur in raw materials to reduce the anode reactivity.

Table 5 - Chemical elements and Lc of uncalcined and calcined bio-coke, and petroleum coke

\begin{tabular}{ccccc} 
& C (\%) & S (\%) & O (\%)* & Lc (nm) \\
\hline Uncalcined bio-coke & 62.7 & 0.222 & 34.7 & 0.23 \\
Calcined bio-coke & 99.8 & 0.016 & 6.2 & 1.04 \\
Petroleum coke & 93.2 & 1.932 & 0.0 & $2.5-3.3$ \\
\hline
\end{tabular}

* Element obtained by EDS.

Bio-coke coke microstructure is strongly influenced by the degree of calcination, which is similar to that of petroleum coke [16]. The crystallite size (Lc) is an indicator of the crystalline structure of coke. The nongraphitic carbon becomes graphitizable during calcination. From a structural viewpoint, calcined bio-coke thus characterizes the state of graphitizable carbon before the beginning of graphitization. As can be seen from this table, the calcination increased the Lc of bio-coke more than 4 times (from 0.23 to $1.04 \mathrm{~nm}$ ). This is probably due to the fact that calcined coke is more aligned than the uncalcined bio-coke [22]. That is, the calcined biocoke is more developed in a graphitic sense during calcination and it becomes less wettable by pitch. However, calcined petroleum coke used in anode manufacture typically has a crystallite size of 2.5-3.3 nm as shown in Table 5 and the Lc value of calcined bio-coke is still lower than that of petroleum coke. More work needs to be done to further increase the Lc of the bio-coke.

\section{Conclusions}

In this study, the interaction mechanism of three coal tar pitches with different properties and bio-cokes before and after calcinations is studied using different techniques. The following conclusions were drawn from the experimental results and their analyses:

- Calcination reduces the wetting capacity as well as the spreading and penetration ability of pitches through bio-coke beds differently depending on the type of pitch used. Initial contact angle and total wetting time are increased and the K-value is decreased with bio-coke calcination. Pitch-1 penetrates into bio-coke faster than pitch-2 and pitch-3. Therefore, pitch-1 found to be best among the pitches studied due to its good affinity for both uncalcined and calcined bio-cokes.

- Calcined bio-coke probably has better strength than uncalcined bio-coke as indicated by their microstructures studied by the means of optical microscopy. Both solid particles (QI) and soluble portion of pitch-1 penetrate completely through the bed of both bio-coke particles and it is evenly distributed in this anisotropic substrate, while those of pitch-2 and pitch-3 are separated and concentrated in large areas. Large QI particles of pitch form a network and act as a sieve which absorbs smaller molecules and prevents other components from penetrating through the bio-coke. The sieve effect of pitch-3 is found to be stronger than that of pitch-2 for both uncalcined and calcined bio-cokes, while these effects are stronger on calcined biocoke than uncalcined bio-coke by the same pitch.

- The SEM results indicate that the three coal tar pitches studied contain no observable mesophase spherules, though pitches-2 and-3 contains bigger primary QI particles. The agglomeration of QI particles might reduce the wettability of uncalcined bio-coke and create cracks due to the differences in shrinkage of different pitch components during cooling. QI particles in pitch cannot easily enter to the cell pores of calcined bio-coke. The size of QI particle in pitch has more important effect on the penetration capacity of QI than the amount of QI particles present in pitch. Small QI particles can easily enter the pore spaces available in bio-coke particles and improve the wetting.

- $\quad$ FTIR results show that the oxygen or nitrogen groups of uncalcined bio-coke can form covalent bonds and assist hydrogen bonding with the hydrogen atoms attached to oxygen or nitrogen atoms in functional groups of pitch, therefore, resulting in good wettability. After calcination, the overall intensity of the infrared 
spectrum decreases along with the loss of oxygen-containing functional groups due to the polymerization of the coke components. Increase of the aromaticity during calcination enhances the resistance of the bio-coke surface to pitch penetration. The spectra of both uncalcined and calcined bio-cokes become similar after they come into contact with a same pitch, but pitch interacts more intensively with uncalcined bio-coke which has higher hydrogen content.

- Calcination increases C\% of bio-coke to more than 99\%, which is higher than that of petroleum coke. Biocokes both before and after calcination have more oxygen and generally less sulfur content in their chemical composition than their petroleum-based counterparts.

- XRD results show that the calcination process enhances the Lc of bio-coke due to the fact that calcined coke is more aligned than the uncalcined bio-coke; consequently it is more difficult to wet by pitch. However, the Lc value of calcined bio-coke is still lower than that of petroleum coke.

\section{Acknowledgements}

The authors thank Natural Sciences and Engineering Research Council of Canada (NSERC) and industrial partner (Boisaco) for their technical and financial contributions as well as Centre universitaire de recherche sur l'aluminium (CURAL) for the technical support during SEM tests. We also thank the Alberta Centre for Surface Engineering and Science (ACSES) at University of Alberta for conducting XPS analyses.

\section{REFERENCES}

[1] J.D. Rocha, A.R. Coutinho, C.A. Luengo, Biopitch produced from eucalyptus wood pyrolysis liquids as a renewable binder for carbon electrode manufacture, Brazilian Journal of Chemical Engineering, 19 (2002) 127-132.

[2] R.-L. Tseng, S.-K. Tseng, F.-C. Wu, Preparation of high surface area carbons from Corncob with KOH etching plus $\mathrm{CO} 2$ gasification for the adsorption of dyes and phenols from water, Colloids and Surfaces A: Physicochemical and Engineering Aspects, 279 (2006) 69-78.

[3] F.-C. Wu, R.-L. Tseng, Preparation of highly porous carbon from fir wood by KOH etching and CO2 gasification for adsorption of dyes and phenols from water, Journal of Colloid and Interface Science, 294 (2006) 21-30.

[4] B.S. Girgis, A.A. Attia, N.A. Fathy, Modification in adsorption characteristics of activated carbon produced by H3PO4 under flowing gases, Colloids and Surfaces A: Physicochemical and Engineering Aspects, 299 (2007) 79-87.

[5] R.-L. Tseng, S.-K. Tseng, Characterization and use of high surface area activated carbons prepared from cane pith for liquid-phase adsorption, Journal of Hazardous Materials, 136 (2006) 671-680.

[6] Y.-J. Kim, B.-J. Lee, H. Suezaki, T. Chino, Y. Abe, T. Yanagiura, K.C. Park, M. Endo, Preparation and characterization of bamboo-based activated carbons as electrode materials for electric double layer capacitors, Carbon, 44 (2006) 1592-1595.

[7] A.R. Coutinho, J.D. Rocha, C.A. Luengo, Preparing and characterizing biocarbon electrodes, Fuel processing technology, 67 (2000) 93-102.

[8] J.M. Burgess, Biomass and renewables as alternative energy sources and reductants in the minerals industry, in, Fremantle, 2004, pp. 9-13.

[9] A.K. Kercher, D.C. Nagle, Microstructural evolution during charcoal carbonization by X-ray diffraction analysis, Carbon, 41 (2003) 15-27.

[10] M.J. Antal Jr, M. Grønli, The art, science, and technology of charcoal production, Industrial and Engineering Chemistry Research, 42 (2003) 1619-1640.

[11] B.E. Monsen, A.P. Ratvik, L.P. Lossius, Charcoal in anodes for aluminium production, in, Seattle, WA, 2010, pp. 929-934.

[12] C. Avila, C.H. Pang, T. Wu, E. Lester, Morphology and reactivity characteristics of char biomass particles, Bioresource Technology, 102 (2011) 5237-5243.

[13] M.J. Wornat, R.H. Hurt, N.Y.C. Yang, T.J. Headley, Structural and compositional transformations of biomass chars during combustion, Combustion and Flame, 100 (1995) 131-143.

[14] F.G. Emmerich, J.C. de Sousa, I.L. Torriani, C.A. Luengo, Applications of a granular model and percolation theory to the electrical resistivity of heat treated endocarp of babassu nut, Carbon, 25 (1987) 417-424.

[15] K. Mochidzuki, F. Soutric, K. Tadokoro, M.J. Antal Jr, M. Tóth, B. Zelei, G. Várhegyi, Electrical and physical properties of carbonized charcoals, Industrial and Engineering Chemistry Research, 42 (2003) 5140-5151. 
[16] K.L. Hulse, Anode Manufacture, in, R\&D Carbon Ltd., New Zealand, 2000.

[17] B. Petrova, T. Budinova, E. Ekinci, N. Petrov, F. Yardim, Influence of pitch composition and surface properties of petroleum coke on their interaction during the preparation of carbon/carbon composites, Carbon, 45 (2007) 704-709.

[18] X. Huang, D. Kocaefe, D. Bhattacharyay, Y. Kocaefe, Morphological and Microstructural Characterization of Bio-coke as Potential Anode Raw Material for Aluminum Industry, in: Materials Science \& Technology 2013, Montreal, Canada, 2013.

[19] J. Lahaye, P. Ehrburger, Pitch-coke interactions, Fuel, 64 (1985) 1187-1191.

[20] P. Couderc, P. Hyvernat, J.L. Lemarchand, Correlations between ability of pitch to penetrate coke and the physical characteristics of prebaked anodes for the aluminium industry, Fuel, 65 (1986) 281-287.

[21] V.G. Rocha, C. Blanco, R. Santamaría, E.I. Diestre, R. Menéndez, M. Granda, An insight into pitch/substrate wetting behaviour. The effect of the substrate processing temperature on pitch wetting capacity, Fuel, 86 (2007) 1046-1052.

[22] E.A. Heintz, WETTING OF FILLER BY BINDER - A SIMPLE APPARATUS FOR DETERMINING WETTING TEMPERATURES, in, American Carbon Soc, Lexington, KY, USA, 1985, pp. 320-321.

[23] J. Cao, A.N. Buckley, A. Tomsett, Re-examining the pitch/coke wetting and penetration test, JOM, 54 (2002) 30-33.

[24] N.A. Adams, Characterization on Pitch Wetting and Penetration Behaviour of Petroleum Coke and Recycled Butts in Prebake Carbon Anode, (2004).

[25] V.G. Rocha, C. Blanco, R. Santamaría, E.I. Diestre, R. Menéndez, M. Granda, Pitch/coke wetting behaviour, Fuel, 84 (2005) 1550-1556.

[26] N.Y. Beilina, E.L. Mizitov, I.A. Bubnenkov, Effect of the nature and degree of anisotropy of cokes on their interaction with coal-tar pitch and its components, Solid Fuel Chemistry, 40 (2007) 44-49.

[27] V.G. Rocha, C. Blanco, R. Santamaría, E.I. Diestre, R. Menéndez, M. Granda, The effect of the substrate on pitch wetting behaviour, Fuel Processing Technology, 91 (2010) 1373-1377.

[28] A. Sarkar, D. Kocaefe, Y. Kocaefe, D. Sarkar, D. Bhattacharyay, B. Morais, J. Chabot, Coke-pitch interactions during anode preparation, Fuel, 117 (2014) 598-607.

[29] S.Q. Shi, D.J. Gardner, Dynamic adhesive wettability of wood, Wood Fiber Sci, 33 (2001) 58-68.

[30] X. Huang, D. Kocaefe, Y. Boluk, Y. Kocaefe, A. Pichette, Effect of surface preparation on the wettability of heat-treated jack pine wood surface by different liquids, European Journal of Wood and Wood Products, 70 (2012) 711-717.

[31] X. Huang, D. Kocaefe, Y. Kocaefe, D. Bhattacharyay, Wettability of bio-coke by coal tar pitch for its use in carbon anodes, Colloids Surf. A Physicochem. Eng. Asp., 490 (2016) 133-144.

[32] T.P. Schultz, Rapid determination of lignocellulose by diffuse reflectance fourier transform infrared spectrometry, Analytical Chemistry, 57 (1985) 2867-2869.

[33] K.K. Pandey, A Study of Chemical Structure of Soft and Hardwood and Wood Polymers by FTIR Spectroscopy, Journal of Applied Polymer Science, 71 (1999) 1969-1975.

[34] A. Ferraz, J. Baeza, J. Rodriguez, J. Freer, Estimating the chemical composition of biodegraded pine and eucalyptus wood by DRIFT spectroscopy and multivariate analysis, Bioresource Technology, 74 (2000) 201-212.

[35] M. Ohkoshi, FTIR-PAS study of light-induced changes in the surface of acetylated or polyethylene glycolimpregnated wood, Journal of Wood Science, 48 (2002) 394-401.

[36] X. Colom, F. Carrillo, F. Nogués, P. Garriga, Structural analysis of photodegraded wood by means of FTIR spectroscopy, Polymer Degradation and Stability, 80 (2003) 543-549.

[37] U. Muller, M. Ratzsch, M. Schwanninger, M. Steiner, H. Zobl, Yellowing and IR-changes of spruce wood as result of UV-irradiation, Journal of Photochemistry and Photobiology B: Biology, 69 (2003) 97-105.

[38] M. Nuopponen, H. Wikberg, T. Vuorinen, S.L. Maunu, S. Ja?msa, P. Viitaniemi, Heat-treated softwood exposed to weathering, Journal of Applied Polymer Science, 91 (2004) 2128-2134.

[39] K.K. Pandey, Study of the effect of photo-irradiation on the surface chemistry of wood, Polymer Degradation and Stability, 90 (2005) 9-20.

[40] B.F. Tjeerdsma, H. Militz, Chemical changes in hydrothermal treated wood: FTIR analysis of combined hydrothermal and dry heat-treated wood, Holz als Roh- und Werkstoff, 63 (2005) 102-111.

[41] G. Nguila Inari, M. Petrissans, P. Gerardin, Chemical reactivity of heat-treated wood, Wood Science and Technology, 41 (2007) 157-168.

[42] K.K. Pandey, T. Vuorinen, Comparative study of photodegradation of wood by a UV laser and a xenon light source, Polymer Degradation and Stability, 93 (2008) 2138-2146.

[43] L. Edwards, F. Vogt, M. Robinette, R. Love, A. Ross, M. McClung, R.J. Roush, W. Morgan, Use of shot coke as an anode raw material, (2009) 985-990.

[44] S.S. Jones, R.D. Hildebrandt, Electrode Binder Pyrolysis and Bond-Coke Microstructure, in, John Wiley and Sons, 2013, pp. 182-197. 
[45] P.J. Ellis, J.D. Bacha, Shot coke, in: Y. Lin Ray, Y.A. Chang, G. Reddy Ramana, C.T. Liu (Eds.), Anaheim, CA, USA, 1996, pp. 477-484.

[46] S.M. Hume, W.K. Fischer, R.C. Perruchoud, J.B. Metson, R.T.K. Baker, Influence of petroleum coke sulphur content on the sodium sensitivity of carbon anodes, in, Publ by Minerals, Metals \& Materials Soc (TMS), Denver, CO, USA, 1993, pp. 535-541.

[47] G.R. Romovacek, The Influence of Solid Particles in Pitch on the Preparation and Baking of the Carbon Blocks, in, John Wiley and Sons, 2013, pp. 225-231.

[48] J. Pinoir, P. Hyvernat, Binding Characteristics of Coal Tar Pitches for Prebaked Anode Mix - Choice Criteria: LRF Report 830, in, John Wiley and Sons, 2013, pp. 215-224.

[49] A. Alscher, R. Wildförster, J.A. Sharp, Performance of Binder Pitches With Decreased QI-Content in Anode Making: Formation - Nature - Properties and Substitution of Quinoline Insolubles, in, John Wiley and Sons, 2013, pp. 232-238.

[50] D.M. Mackay, P.V. Roberts, The influence of pyrolysis conditions on yield and microporosity of lignocellulosic chars, Carbon, 20 (1982) 95-104.

[51] L.F. Hawley, Wood Distillation, Chemical Catalog Co., New York, 1923.

[52] L.B. Khalil, Porosity characteristics of chars derived from different lignocellulosic materials, Adsorption Science and Technology, 17 (1999) 729-739.

[53] X. Huang, D. Kocaefe, Y. Kocaefe, D. Bhattacharyay, A structural and chemical study on wettability of bio-coke by coal tar pitch during the preparation of carbon anode used in aluminum production, Carbon, (2014).

[54] E.A. Heintz, Influence of coke structure on the properties of the carbon-graphite artefact, Fuel, 64 (1985) 1192-1196. 